\title{
Ligand-Induced Tunable Dual-Color Emission Based on Lead Halide Perovskites for White Light-Emitting
}

\section{Diodes}

Yifei Yue ${ }^{\dagger}$, Dongxia Zhu ${ }^{*, \dagger}$, Ning Zhang ${ }^{*,}$, Guangshan Zhu, ${ }^{\dagger}$ Zhongmin $\mathrm{Su}^{\dagger, *}$

${ }^{\dagger}$ Key Laboratory of Nanobiosensing and Nanobioanalysis at Universities of Jilin Province, Department of Chemistry, Northeast Normal University, 5268 Renmin Street, Changchun, Jilin Province 130024, P. R. China.

\$School of Chemistry and Environmental Engineering, Changchun University of Science and Technology, Changchun, 130022, P. R. China.

Corresponding Author

*E-mail: zhangn380@nenu.edu.cn

\section{Supporting Information}

\section{Experimental Methods}

\section{Materials.}

Cesium carbonate $\left(\mathrm{Cs}_{2} \mathrm{CO}_{3}, 99.9 \%\right.$ ), oleic acid (OA, 90\%), oleylamine (OLA, 90\%), Methoxypolyethylene glycols-200 (MEOPEG), 2-methoxyethanol (2-methoxyethanol, 99.0\%), Methoxypolyethylene glycols-2000 (MEOPEG 2000), lead chloride $\left(\mathrm{PbCl}_{2}, 99.999 \%\right)$, lead bromide $\left(\mathrm{PbBr}_{2}, 99.999 \%\right)$, lead iodide $\left(\mathrm{PbI}_{2}, 99 \%\right)$, 1-octadecene (ODE, 90\%), ethyl acetate (EA, 99.5\%), cyclohexane (CYH, 99.5\%). All chemicals were directly used without further purification.

Synthesis of Cs-oleate solution.

$\mathrm{Cs}_{2} \mathrm{CO}_{3}(0.8 \mathrm{~g}), \mathrm{OA}(2.5 \mathrm{~mL})$ and $\mathrm{ODE}(30.0 \mathrm{~mL})$ were loaded into a $50 \mathrm{~mL}$ round bottom flask and heated under $\mathrm{N}_{2}$ at $130{ }^{\circ} \mathrm{C}$ for $40 \mathrm{~min}$. The mixture was then heated to $150{ }^{\circ} \mathrm{C}$ for $20 \mathrm{~min}$ until $\mathrm{Cs}_{2} \mathrm{CO}_{3}$ powder totally dissolved. The solution was cooled down to room temperature and stored in the desiccator. The solution was preheated to $60{ }^{\circ} \mathrm{C}$ just before use.

Synthesis of $\mathrm{CsPbBr}_{3}-\mathrm{MEOPEG}$.

$\mathrm{PbBr}_{2}$ (0.2642 g), OA (2 mL), OLA (2 mL), MEOPEG-200 (2 mL) and ODE (20.0 mL) were loaded into a $50 \mathrm{~mL}$ 2-neck round bottom flask and heated under $\mathrm{N}_{2}$ at $100{ }^{\circ} \mathrm{C}$ for 40 min until $\mathrm{PbBr}_{2}$ powder totally dissolved. Then Cs-oleate solution $(2 \mathrm{~mL})$ was injected quickly into the solution. The mixture was kept at $100{ }^{\circ} \mathrm{C}$ for $20 \mathrm{~min}$ for the growth of NWs. Then the mixture was cooled down to room temperature quickly by ice-water bath. EA $(175 \mathrm{~mL})$ was added into the mixture and stirred for $3 \mathrm{~h}$. The product was obtained by centrifuging and purified by moderate EA. 
Synthesis of $\mathrm{CsPbBr}_{3}$-Washed.

$\mathrm{CsPbBr}$-MEOPEG $(100 \mathrm{mg})$ and EA $(10 \mathrm{~mL})$ were loaded into a $50 \mathrm{~mL}$ centrifuge tube. Then the mixture was ultrasonically shaken for 5 minutes. The supernatant was removed after centrifugation. Repeat the above steps 3 times. The product was dried under vacuum at $60{ }^{\circ} \mathrm{C}$ for $6 \mathrm{~h}$.

Synthesis of $\mathrm{CsPbrr}_{3}-\mathrm{OA} / \mathrm{OLA}$.

$\mathrm{PbBr}_{2}(0.2642 \mathrm{~g}), \mathrm{OA}(2 \mathrm{~mL})$, OLA $(2 \mathrm{~mL})$ and ODE $(20.0 \mathrm{~mL})$ were loaded into a $50 \mathrm{~mL}$ 2-neck round bottom flask and heated under $\mathrm{N}_{2}$ at $100{ }^{\circ} \mathrm{C}$ for 40 min until $\mathrm{PbBr}_{2}$ powder totally dissolved. Then Cs-oleate solution $(2 \mathrm{~mL})$ was injected quickly into the solution. The mixture was kept at $100{ }^{\circ} \mathrm{C}$ for 20 min for the growth of NWs. Then the mixture was cooled down to room temperature quickly by ice-water bath. EA (175 $\mathrm{mL}$ ) was added into the mixture and stirred for $3 \mathrm{~h}$. The product was obtained by centrifuging and purified by moderate EA.

Synthesis of $\mathrm{CsPbr}_{3}$-2-methoxyethanol.

$\mathrm{PbBr}_{2}(0.2642 \mathrm{~g})$, OA (2 mL), OLA (2 mL), 2-methoxyethanol (1.98 g) and ODE (20.0 mL) were loaded into a $50 \mathrm{~mL}$ 2-neck round bottom flask and heated under $\mathrm{N}_{2}$ at $100{ }^{\circ} \mathrm{C}$ for 40 min until $\mathrm{PbBr}_{2}$ powder totally dissolved. Then Cs-oleate solution $(2 \mathrm{~mL})$ was injected quickly into the solution. The mixture was kept at $100{ }^{\circ} \mathrm{C}$ for $20 \mathrm{~min}$ for the growth of perovskites. Then the mixture was cooled down to room temperature quickly by ice-water bath. EA $(175 \mathrm{~mL})$ was added into the mixture and stirred for $3 \mathrm{~h}$. The product was obtained by centrifuging and purified by moderate EA.

Synthesis of $\mathrm{CsPbBr}_{3}-\mathrm{MEOPEG} 2000$

$\mathrm{PbBr}_{2}(0.2642 \mathrm{~g}), \mathrm{OA}(2 \mathrm{~mL}), \mathrm{OLA}(2 \mathrm{~mL})$, MEOPEG 2000 (1.98 g) and ODE (20.0 mL) were loaded into a $50 \mathrm{~mL}$ 2-neck round bottom flask and heated under $\mathrm{N}_{2}$ at $100{ }^{\circ} \mathrm{C}$ for 40 min until $\mathrm{PbBr}_{2}$ powder totally dissolved. Then Cs-oleate solution $(2 \mathrm{~mL})$ was injected quickly into the solution. The mixture was kept at $100{ }^{\circ} \mathrm{C}$ for $20 \mathrm{~min}$ for the growth of perovskites. Then the mixture was cooled down to room temperature quickly by ice-water bath. EA $(175 \mathrm{~mL})$ was added into the mixture and stirred for $3 \mathrm{~h}$. The product was obtained by centrifuging and purified by moderate EA.

Synthesis of $\mathrm{CsPbBr}_{3}$-MEOPEG with different concentrations of surface ligands.

$\mathrm{PbBr}_{2}(0.2642 \mathrm{~g})$, OA (1.0 mL, $\left.0.6 \mathrm{~mL}, 0.5 \mathrm{~mL}\right)$, OLA (1.0 mL, $\left.0.6 \mathrm{~mL}, 0.5 \mathrm{~mL}\right)$, MEOPEG-200 (1.0 mL, $0.6 \mathrm{~mL}, 0.5 \mathrm{~mL})$ and ODE $(20.0 \mathrm{~mL})$ were loaded into a $50 \mathrm{~mL}$ 2-neck round bottom flask and heated under $\mathrm{N}_{2}$ at $100{ }^{\circ} \mathrm{C}$ for 40 min until $\mathrm{PbBr}_{2}$ powder totally dissolved. Then Cs-oleate solution $(2 \mathrm{~mL})$ was injected quickly into the solution. The mixture was kept at $100{ }^{\circ} \mathrm{C}$ for $20 \mathrm{~min}$ for the growth of NWs. Then the mixture was cooled down to room temperature quickly by ice-water bath. EA $(175 \mathrm{~mL})$ was added into the mixture and stirred for $3 \mathrm{~h}$. The product was obtained by centrifuging and purified by moderate EA.

Synthesis of $\mathrm{PbX}_{2}$ precursor stock solutions.

$\mathrm{PbX}_{2}$ (1.2 mmol, 0.3337g for $\mathrm{PbCl}_{2}, 0.5532 \mathrm{~g}$ for $\left.\mathrm{PbI}_{2}\right)$, OA (2.4 mL for $\mathrm{PbCl}_{2}, 1.2 \mathrm{~mL}$ for $\left.\mathrm{PbI}_{2}\right)$, OLA (2.4 $\mathrm{mL}$ for $\mathrm{PbCl}_{2}, 1.2 \mathrm{~mL}$ for $\left.\mathrm{PbI}_{2}\right)$, and $\mathrm{CYH}(10 \mathrm{~mL})$ were loaded into a $25 \mathrm{~mL}$ round bottom flask and heated to reflux under $\mathrm{N}_{2}$ for 40 min until the powder totally dissolved. The $\mathrm{PbX}_{2}$ precursor stock solutions were cooled down to room temperature and stored at room temperature.

Post-synthetic anion exchange of $\mathrm{CsPbr}_{3}-\mathrm{MEOPEG}$.

Post-synthetic anion exchange was performed with $\mathrm{PbX}_{2}$ precursor stock solutions at room temperature. $\mathrm{CsPbBr}$-MEOPEG was dispersed in different concentrations precursor stock solutions at room temperature with vigorous stirring for $40 \mathrm{~min}$. The product $\mathrm{CsPb}(\mathrm{Br} / \mathrm{Cl})_{3}$-MEOPEG and $\mathrm{CsPb}(\mathrm{Br} / \mathrm{I})_{3}-\mathrm{MEOPEG}$ were obtained by centrifuging and purified by moderate $\mathrm{CYH}$. 
Post-synthetic anion exchange of $\mathrm{CsPbBr}_{3}$-Washed.

$\mathrm{CsPbBr}$-Washed was obtained by washing $\mathrm{CsPbBr}$-MEOPEG (100 mg) with EA. These $\mathrm{CsPbBr}_{3} \mathrm{Fere}$ dispersed in $10 \mathrm{ml} \mathrm{PbX}_{2}$ precursor stock solutions with vigorous stirring for $40 \mathrm{~min}$. The product $\mathrm{CsPb}(\mathrm{Br} / \mathrm{Cl})_{3}$ and $\mathrm{CsPb}(\mathrm{Br} / \mathrm{I})_{3}$ were obtained by centrifuging and purified by moderate $\mathrm{CYH}$.

Fabrication of WLEDs.

CsPbBr 3 -MEOPEG $1.0 \mathrm{~mL}(15 \mathrm{mg}), \mathrm{PbCl}_{2}$ precursor stock solution $(0.165 \mathrm{~mL})$ and $\mathrm{CYH}(0.835 \mathrm{~mL})$ were loaded into a $10 \mathrm{~mL}$ centrifuge tube with vigorous stirring for $40 \mathrm{~min}$.

$\mathrm{CsPbBr}_{3}$-MEOPEG 1.0mL (30 mg), $\mathrm{PbI}_{2}$ precursor stock solution $(0.335 \mathrm{~mL})$ and $\mathrm{CYH}(0.665 \mathrm{~mL})$ were loaded into a $10 \mathrm{~mL}$ centrifuge tube with vigorous stirring for $40 \mathrm{~min}$.

$\mathrm{CsPb}(\mathrm{Br} / \mathrm{Cl})_{3}$-MEOPEG solution $(0.3 \mathrm{~mL})$ was dripped onto the surface of clean quartz plate $(2.0 \mathrm{~cm} \times 2.0$ $\mathrm{cm})$. Then dry naturally in the atmosphere for $10 \mathrm{~min}$. A same clean quartz plate was put on this film. $\mathrm{CsPb}(\mathrm{Br} / \mathrm{I})_{3}$-MEOPEG solution $(0.3 \mathrm{~mL})$ was dripped onto the surface of the second quartz plate. Then dry naturally in the atmosphere for $10 \mathrm{~min}$.

\section{Characterization.}

Solid-state XRD patterns were recorded using an X-ray diffractometer with SmartLab system. TEM and HRTEM images were obtained from the JEOL-2100F electron microscope. FT-IR tests were performed on a Magna 560 FTIR spectrometer with $\mathrm{KBr}$ disks. ${ }^{1} \mathrm{H}$ NMR spectra were acquired on a Varian $500 \mathrm{MHz}$ AVANCE Bruker spectrometer with the solutions in Dimethyl sulfoxide-d6. XPS analyses were performed on a Quantum 2000 spectrometer. In XPS measurement, MEOPEG 2000 solid was substituted for MEOPEG that is liquid at room temperature. UPS spectra were obtained from Thermo ESCALAB. The wt $\%$ of the surface ligands were obtained by differential thermal gravity though DTG-60H. The contents of halogens were obtained from EDS of HITACHI SU8010 scanning electron microscope. Absorption spectra were obtained by UV-Vis-NIR Spectrophotometer with a calibrated integrating sphere. PL spectra were collected by a Shimadzu RF-5301pc spectrophotometer. CIE coordinate and CRI were obtained from SpectraScan PR655.<smiles>COCCOCCOCCOCCO</smiles>

Figure S1. Structural formula of MEOPEG.
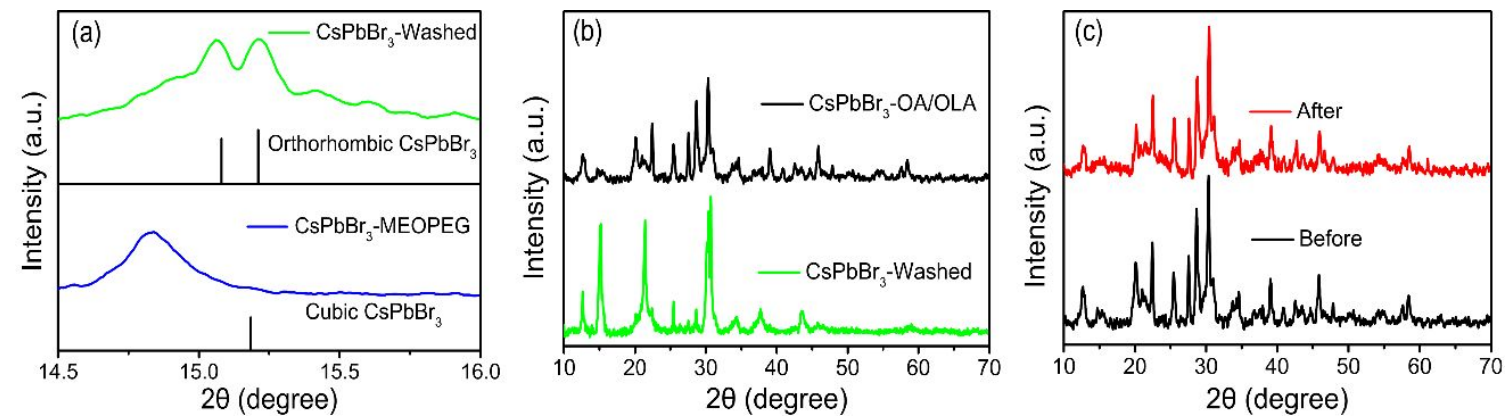

Figure S2. a) Enlarged (from 14.5 to 16.0 degrees) solid-state XRD patterns of $\mathrm{CsPBr}_{3}-\mathrm{MEOPEG}$ and $\mathrm{CsPBBr}_{3}$-Washed. b) Solid-state XRD patterns of $\mathrm{CsPbBr}_{3}-\mathrm{OA} / \mathrm{OLA}$ and $\mathrm{CsPbBr}_{3}$-Washed. c) Solid-state $\mathrm{XRD}$ patterns of $\mathrm{CsPbBr}_{3}-\mathrm{OA} / \mathrm{OLA}$ before and after ultrasonication. 

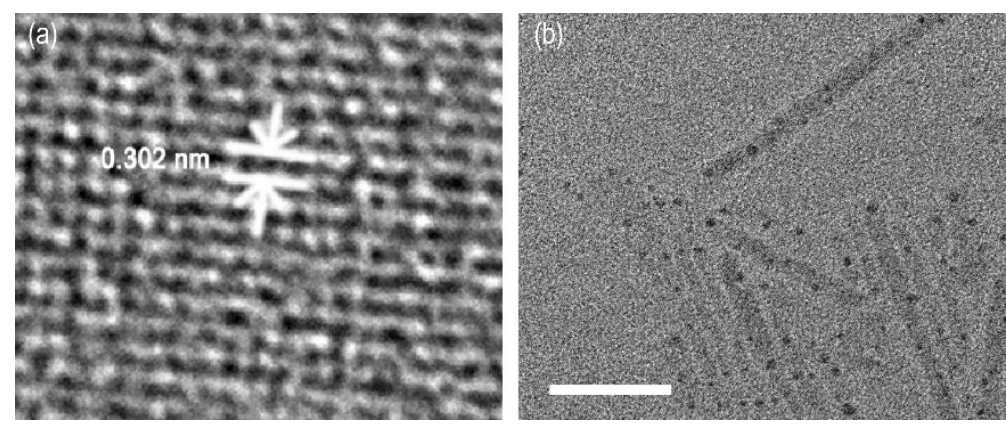

Figure S3. a) HRTEM image of $\mathrm{Pb}$ dot and b) TEM image of $\mathrm{CsPbBr}$-Washed (scale bar is $50 \mathrm{~nm}$ ).
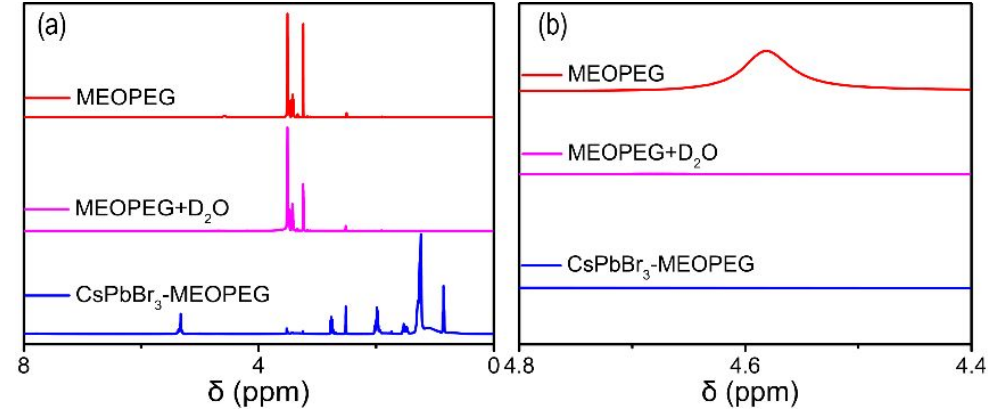

Figure S4. ${ }^{1} \mathrm{H}$ NMR a) full and b) enlarged (from 4.4 to $4.8 \mathrm{ppm}$ ) spectra of MEOPEG, MEOPEG+ $\mathrm{D}_{2} \mathrm{O}$ and $\mathrm{CsPbBr}$-MEOPEG.
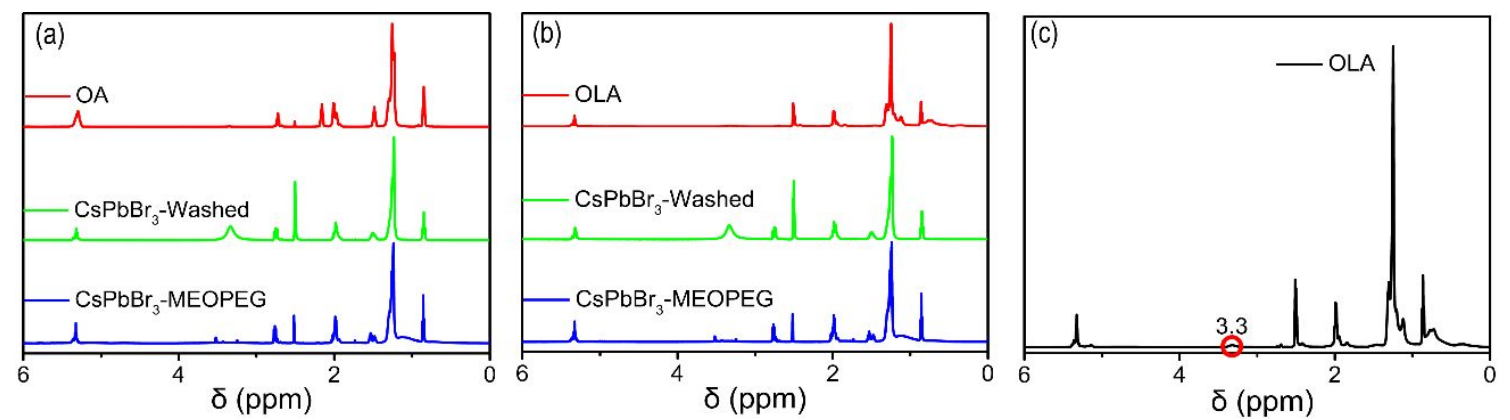

Figure S5. ${ }^{1} \mathrm{H}$ NMR spectra of $\mathrm{CsPbBr}_{3}-\mathrm{MEOPEG}, \mathrm{CsPbBr}{ }_{3}$-Washed and a) OA, b) OLA. c) ${ }^{1} \mathrm{H}$ NMR spectrum of OLA.

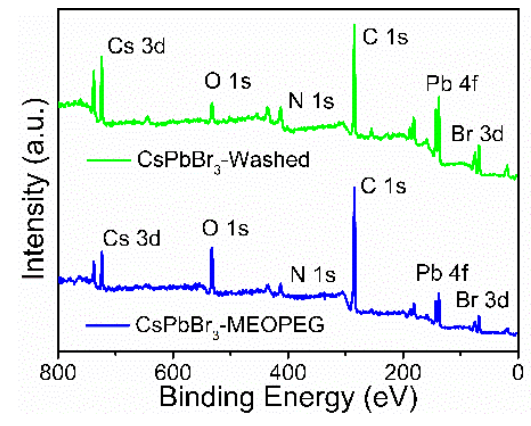

Figure S6. Overview XPS spectra of $\mathrm{CsPbBr}$ - $\mathrm{MEOPEG}$ and $\mathrm{CsPbBr}$-Washed. 

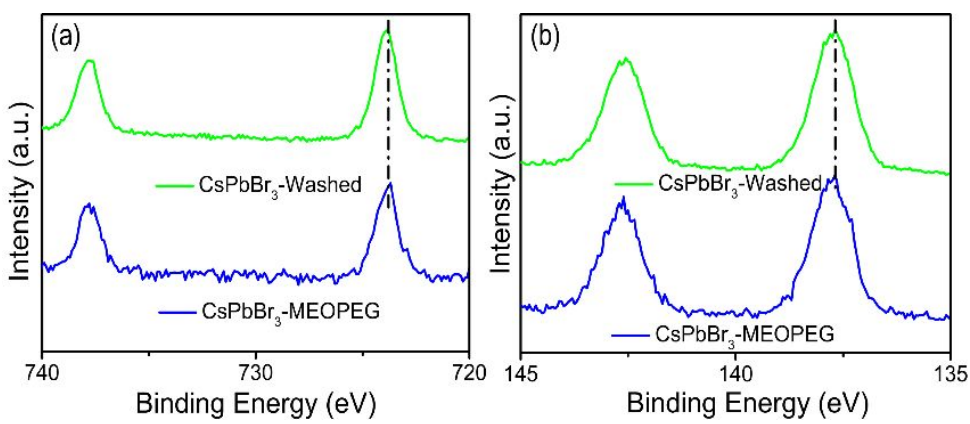

Figure S7. XPS core level spectra of a) $\mathrm{Cs} 3 \mathrm{~d}$ and b) $\mathrm{Pb} 4 \mathrm{f}$ for $\mathrm{CsPBBr}_{3}-\mathrm{MEOPEG}$ and $\mathrm{CsPbBr}_{3}$-Washed.
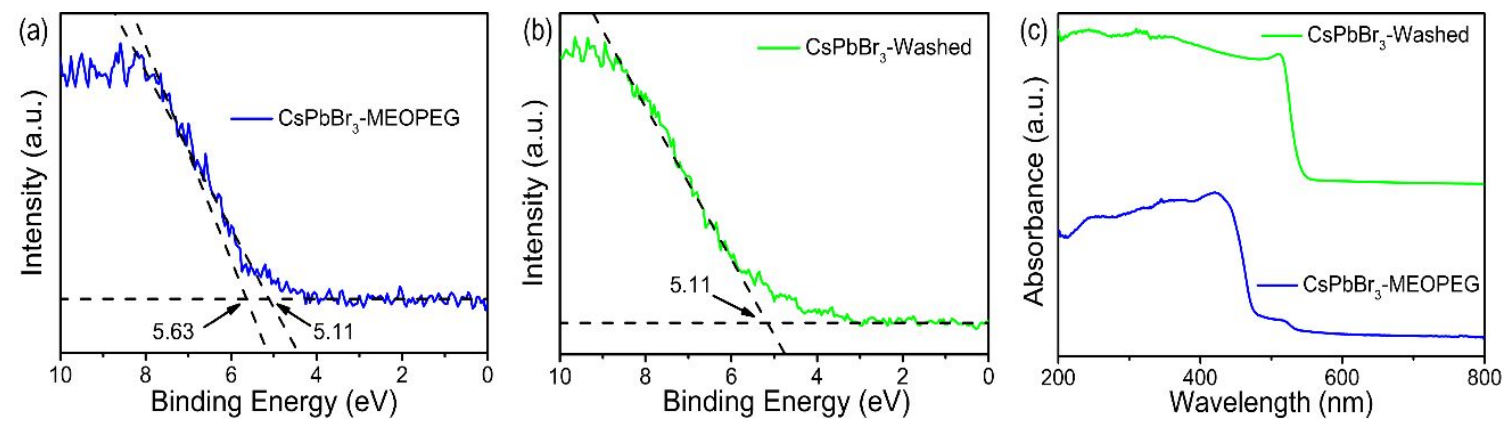

Figure S8. UPS spectra of a) $\mathrm{CsPbBr}_{3}-\mathrm{MEOPEG}$ and b) $\mathrm{CsPBrr}_{3}$-Washed films deposited on $\mathrm{Si}$ substrates.

c) Absorption spectra of $\mathrm{CsPBr}_{3}-\mathrm{MEOPEG}$ and $\mathrm{CsPbBr}_{3}$-Washed.

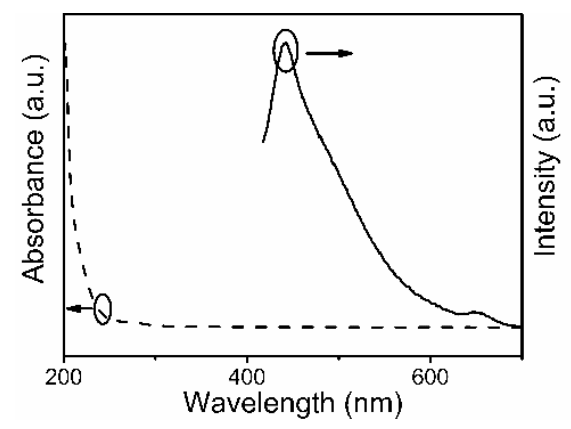

Figure S9. Photoluminescence (full lines, $390 \mathrm{~nm}$ excitation) and absorption (dashed lines) spectra of MEOPEG.<smiles>COCCO</smiles>

Figure S10. Structural formula of 2-methoxyethanol.<smiles>COCCO[14CH2]CO</smiles>

Figure S11. Structural formula of MEOPEG 2000.
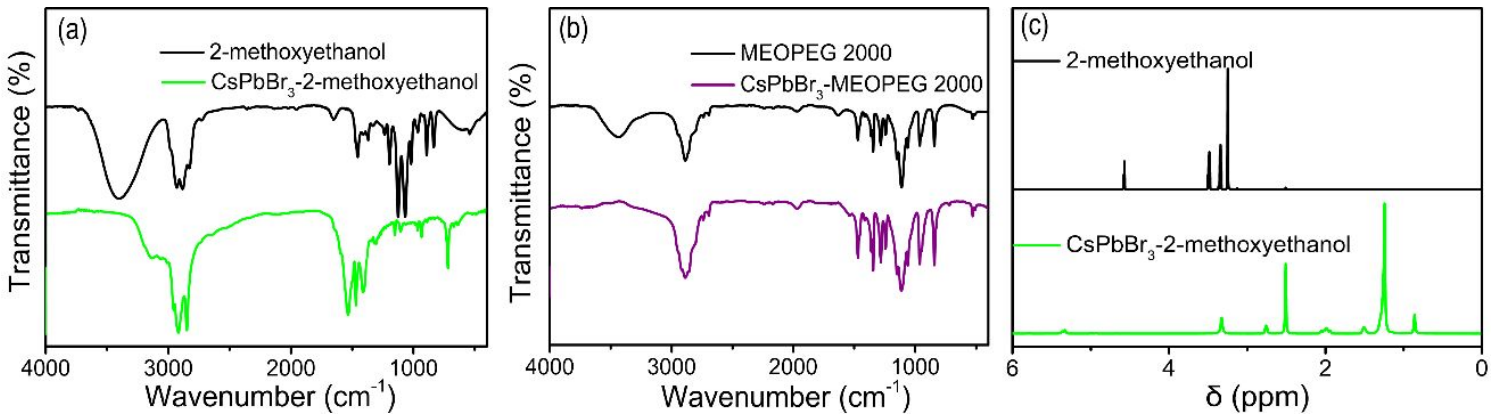
Figure S12. FTIR spectra of a) $\mathrm{CsPbBr}_{3}$-2-methoxyethanol and b) $\mathrm{CsPbBr}_{3}-\mathrm{MEOPEG} 2000$. c) ${ }^{1} \mathrm{H}$ NMR spectra of 2-methoxyethanol and $\mathrm{CsPBBr}_{3}$-2-methoxyethanol.
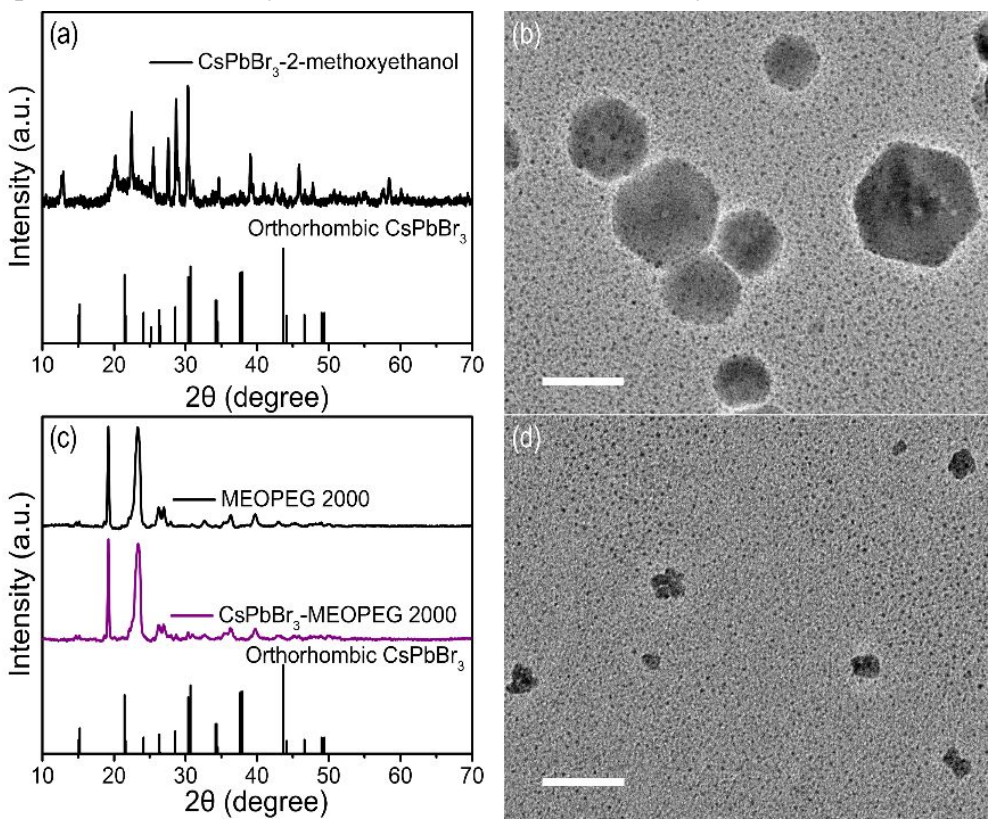

Figure S13. a) Solid-state XRD pattern of $\mathrm{CsPbBr}_{3}$-2-methoxyethanol, and b) TEM image of $\mathrm{CsPbBr}_{3}$-2-methoxyethanol (scale bar is $50 \mathrm{~nm}$ ). c) Solid-state XRD patterns of MEOPEG 2000 and $\mathrm{CsPbBr}_{3}$-MEOPEG 2000. d) TEM image of $\mathrm{CsPbBr}_{3}$-MEOPEG 2000 (scale bar is $50 \mathrm{~nm}$ ).
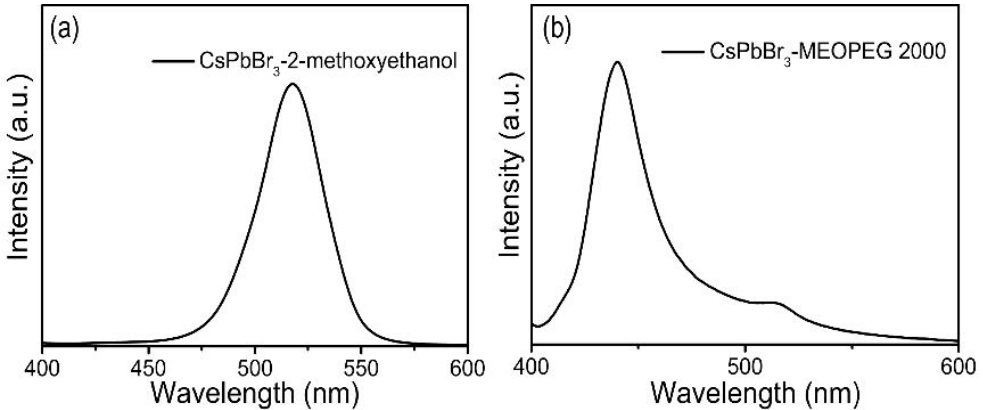

Figure S14. Photoluminescence spectra (390 nm excitation) of a) $\mathrm{CsPbBr}_{3}$-2-methoxyethanol and b) $\mathrm{CsPbBr}_{3}$-MEOPEG 2000.
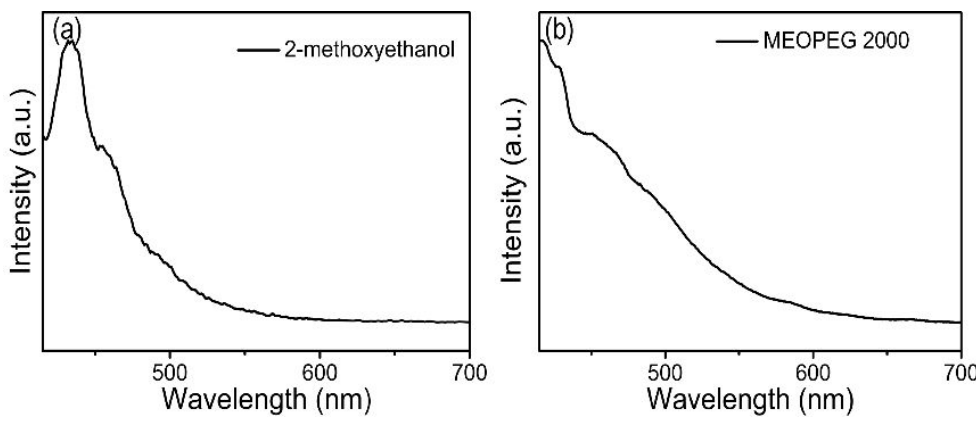

Figure S15. a) Photoluminescence spectra (390 nm excitation) of 2-methoxyethanol and b) MEOPEG 2000. 

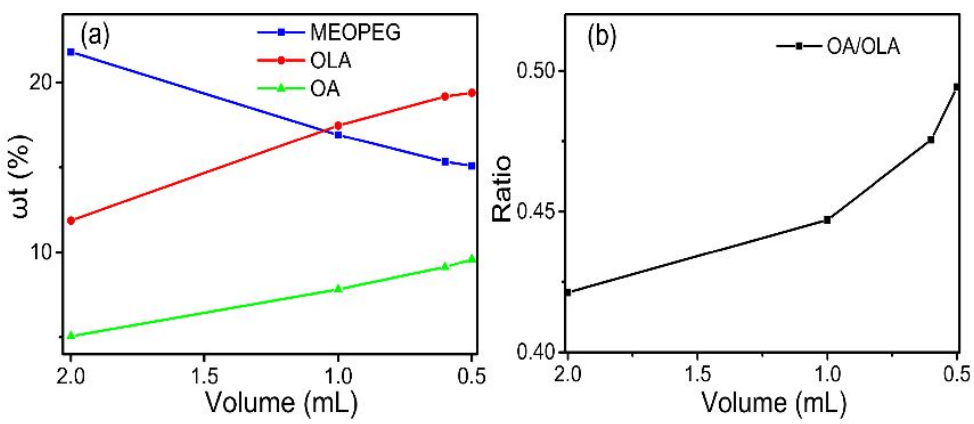

Figure S16. a) The $w t \%$ of ligands and b) the ratio of OA to OLA in $\mathrm{CsPbBr}_{3}$-MEOPEG with different concentration of surface ligands.

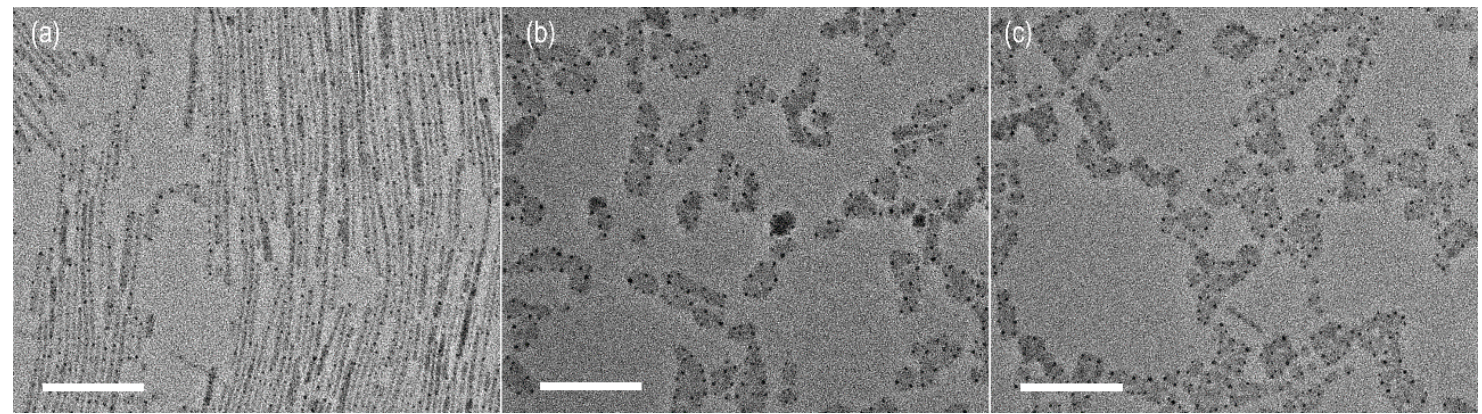

Figure S17. TEM images of $\mathrm{CsPbBr}_{3}$-MEOPEG with different concentration of surface ligands a) $1.0 \mathrm{~mL}$, b) $0.6 \mathrm{~mL}$ and c) $0.5 \mathrm{~mL}$ (scale bar is $100 \mathrm{~nm}$ ).
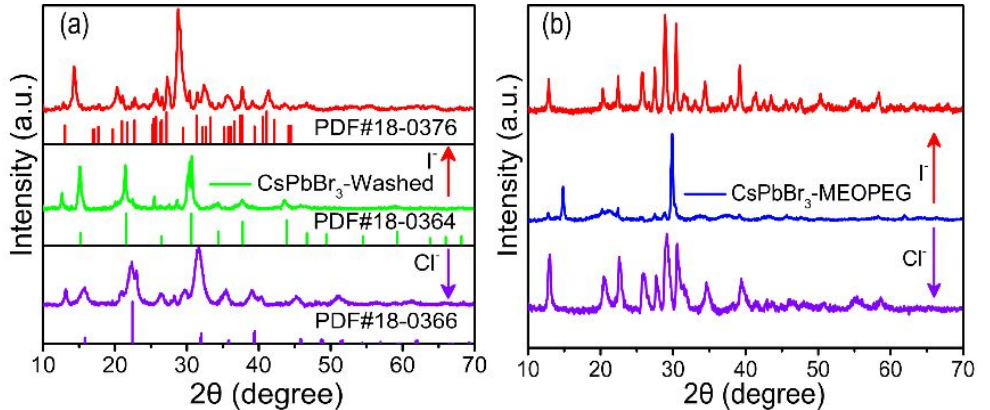

Figure S18. Solid-state XRD patterns of a) $\mathrm{CsPbBr}_{3}$-Washed and b) $\mathrm{CsPbBr}_{3}-\mathrm{MEOPEG}$ after anion exchange.
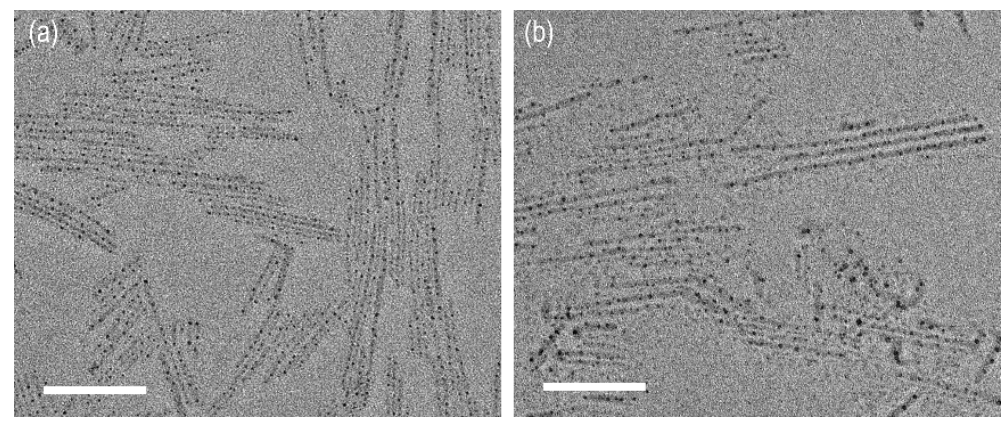

Figure S19. TEM images of a) $\mathrm{CsPb}(\mathrm{Br} / \mathrm{Cl})_{3}$-MEOPEG and b) $\mathrm{CsPb}(\mathrm{Br} / \mathrm{I})_{3}$-MEOPEG (scale bar is $100 \mathrm{~nm}$ ). 

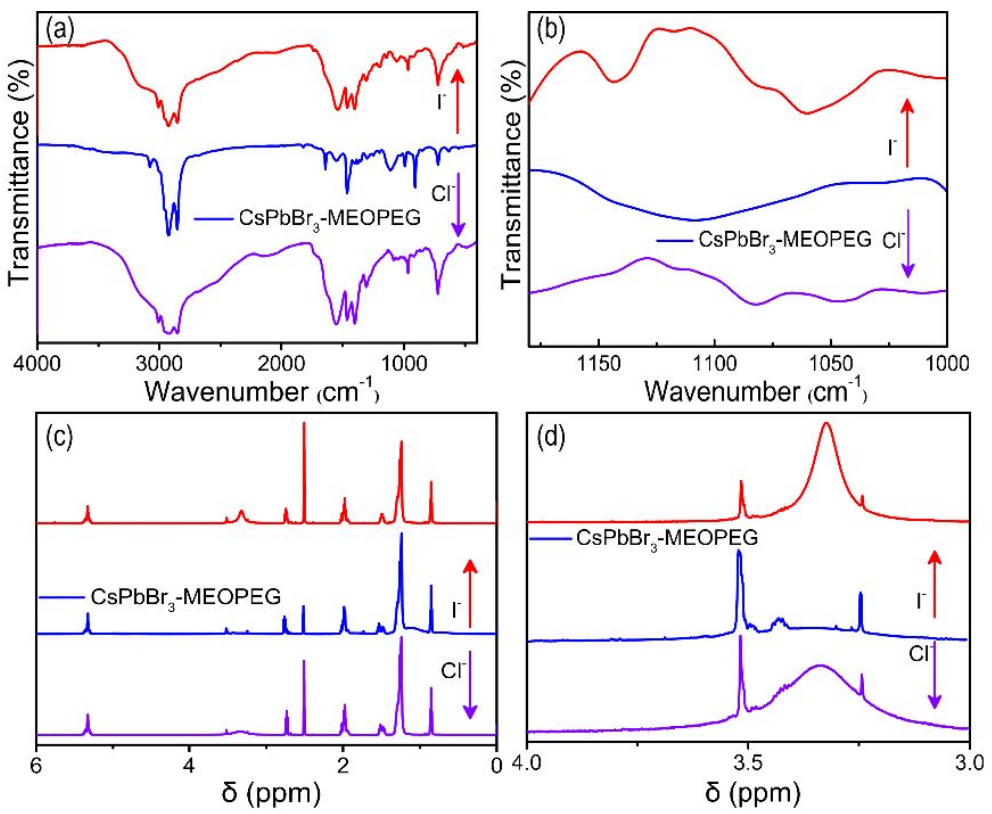

Figure S20. FTIR a) full and b) enlarged (from 1000 to $1180 \mathrm{~cm}^{-1}$ ) spectra of $\mathrm{CsPbBr}_{3}-\mathrm{MEOPEG}$ after anion exchange. ${ }^{1} \mathrm{H}$ NMR c) full and d) enlarged (from 3.0 to $4.0 \mathrm{ppm}$ ) spectra of $\mathrm{CsPbBr}_{3}-\mathrm{MEOPEG}$ after anion exchange.
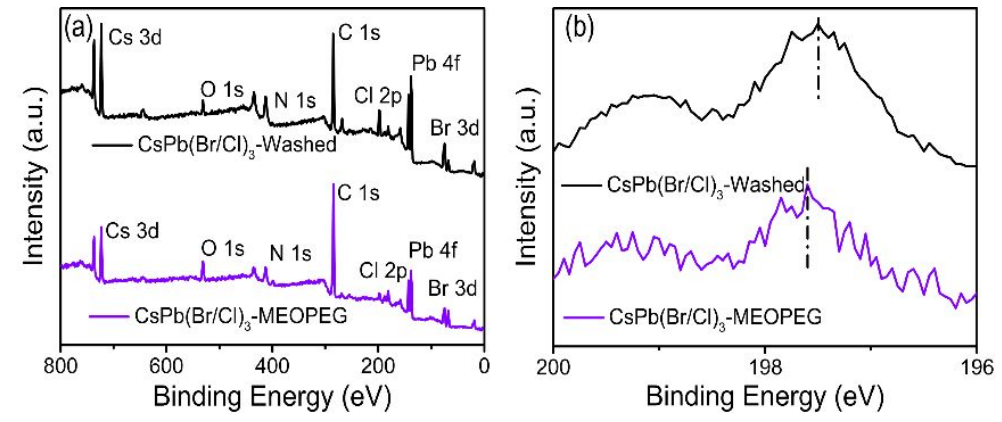

Figure S21. Overview XPS spectra of a) $\mathrm{CsPb}(\mathrm{Br} / \mathrm{Cl})_{3}-\mathrm{MEOPEG}$ and $\mathrm{CsPb}(\mathrm{Br} / \mathrm{Cl})_{3}$-Washed and b) XPS core level spectra of $\mathrm{Cl} 2 \mathrm{p}$ for $\mathrm{CsPb}(\mathrm{Br} / \mathrm{Cl})_{3}-\mathrm{MEOPEG}$ and $\mathrm{CsPb}(\mathrm{Br} / \mathrm{Cl})_{3}$-Washed.
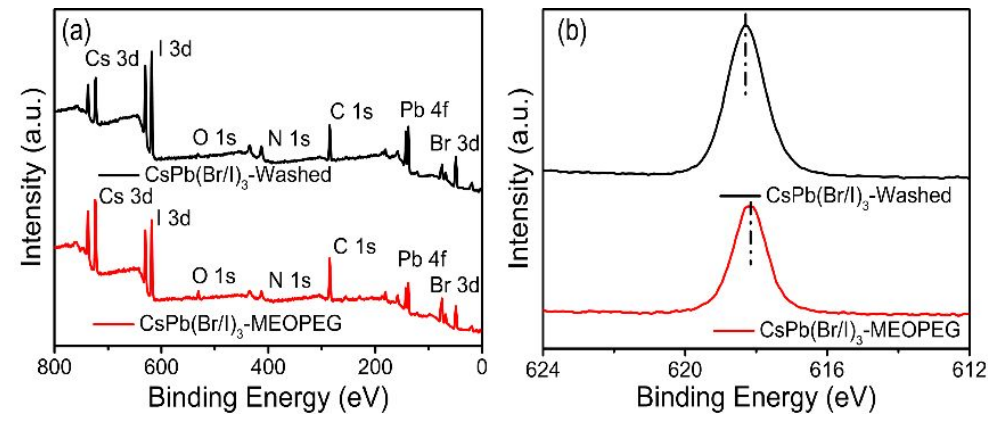

Figure S22. Overview XPS spectra of a) $\mathrm{CsPb}(\mathrm{Br} / \mathrm{I})_{3}$-MEOPEG and $\mathrm{CsPb}(\mathrm{Br} / \mathrm{I})_{3}$-Washed and b) XPS core level spectra of $\mathrm{I} 3 \mathrm{~d}$ for $\mathrm{CsPb}(\mathrm{Br} / \mathrm{I})_{3}-\mathrm{MEOPEG}$ and $\mathrm{CsPb}(\mathrm{Br} / \mathrm{I})_{3}$-Washed. 

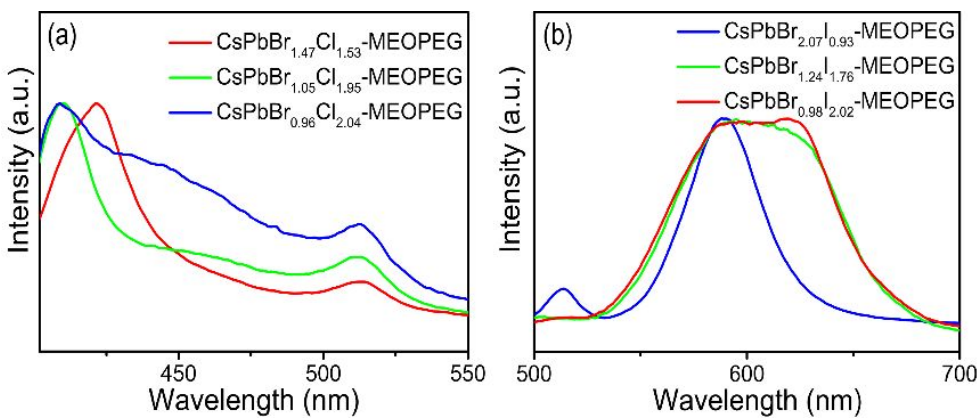

Figure S23. Photoluminescence spectra (390 nm excitation) of $\mathrm{CsPbBr}_{3}-\mathrm{MEOPEG}$ after various degrees of anion exchange reaction.

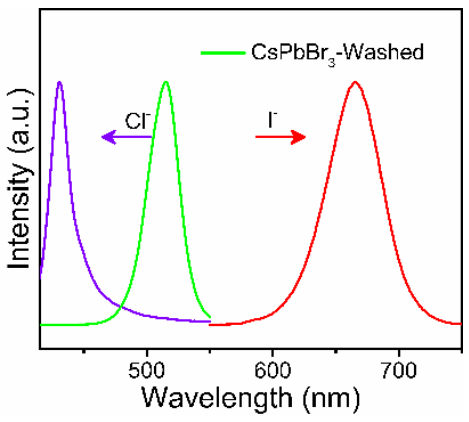

Figure S24. Photoluminescence spectra (390 nm excitation) of $\mathrm{CsPbBr}_{3}$-Washed after anion exchange reaction.

Table S1. $\mathrm{CsPBr}_{3}-\mathrm{MEOPEG}$ synthesized with various amount of MEOPEG, OA and OLA.

\begin{tabular}{|c|c|c|c|}
\hline & MEOPEG & OA & OLA \\
\hline $\mathrm{CsPbBr}_{3}$-MEOPEG $2.0 \mathrm{~mL}$ & $2.0 \mathrm{~mL}$ & $2.0 \mathrm{~mL}$ & $2.0 \mathrm{~mL}$ \\
\hline $\mathrm{CsPbBr}_{3}$-MEOPEG $1.0 \mathrm{~mL}$ & $1.0 \mathrm{~mL}$ & $1.0 \mathrm{~mL}$ & $1.0 \mathrm{~mL}$ \\
\hline $\mathrm{CsPbBr}_{3}$-MEOPEG $0.6 \mathrm{~mL}$ & $0.6 \mathrm{~mL}$ & $0.6 \mathrm{~mL}$ & $0.6 \mathrm{~mL}$ \\
\hline $\mathrm{CsPbBr}_{3}$-MEOPEG $0.5 \mathrm{~mL}$ & $0.5 \mathrm{~mL}$ & $0.5 \mathrm{~mL}$ & $0.5 \mathrm{~mL}$ \\
\hline
\end{tabular}

Table S2. $\lambda_{\text {em }}$ of $\mathrm{CsPbBr}_{3}$-MEOPEG covered by various amount of MEOPEG, OA and OLA.

\begin{tabular}{|c|c|c|c|c|}
\hline $\begin{array}{c}\mathrm{CsPbBr}_{3}-\mathrm{MEOPE} \\
\mathrm{G}\end{array}$ & $2.0 \mathrm{~mL}$ & $1.0 \mathrm{~mL}$ & $0.6 \mathrm{~mL}$ & $0.5 \mathrm{~mL}$ \\
\hline$\lambda_{\mathrm{em} 1}(\mathrm{~nm})$ & 470 & 463 & 461 & 460 \\
\hline$\lambda_{\mathrm{em} 2}(\mathrm{~nm})$ & 515 & 510 & 509 & 502 \\
\hline
\end{tabular}

Table S3. The change in the chemical environment of halogens of $\mathrm{CsPbB}_{3}-\mathrm{MEOPEG}$ after anion exchange.

\begin{tabular}{|c|c|c|c|}
\hline Halogen & $\mathrm{Cl}$ in $\mathrm{CsPb}(\mathrm{Br} / \mathrm{Cl})_{3}$-MEOPEG & ${\mathrm{Br} \text { in } \mathrm{CsPbBr}_{3} \text {-MEOPEG }}$ I in $\mathrm{CsPb}(\mathrm{Br} / \mathrm{I})_{3}$-MEOPEG \\
\hline $\begin{array}{c}\text { D-value } \\
(\mathrm{eV})\end{array}$ & 0.10 & 0.15 & 0.08 \\
\hline
\end{tabular}

